\title{
Amyl Nitrite Induced Hemolytic Anemia: Acute Therapy and Prevention
}

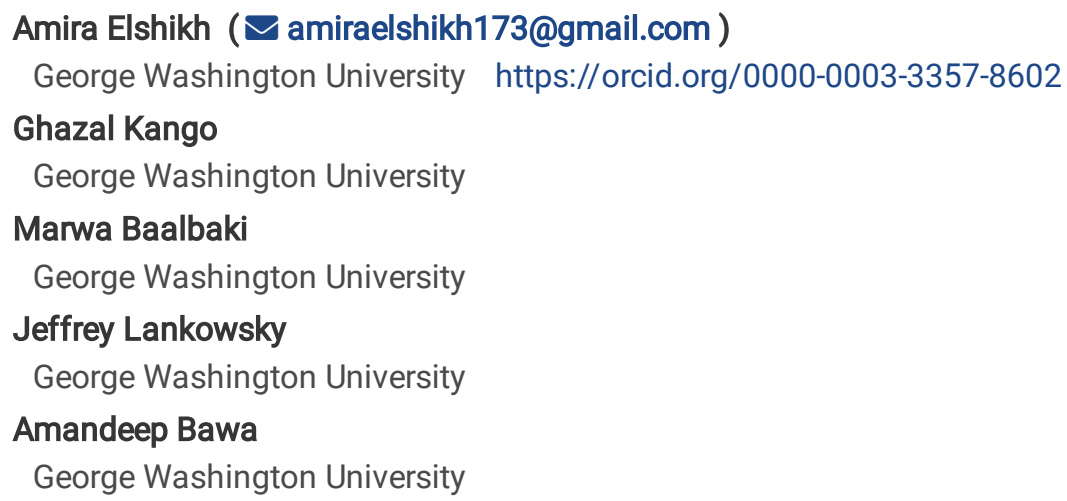

Keywords: Acute hemolytic anemia, methemoglobinemia, inhaled nitrites, G6PD deficiency, methylene blue, substance recreational use, MSM, provider awareness

Posted Date: July 20th, 2020

DOI: https://doi.org/10.21203/rs.3.rs-42399/v1

License: (c) (i) This work is licensed under a Creative Commons Attribution 4.0 International License. Read Full License

Version of Record: A version of this preprint was published at Cureus on July 1st, 2021. See the published version at https://doi.org/10.7759/cureus.16099. 


\section{Abstract \\ Background:}

Inhaled nitrites have been a substance of recreational use for centuries, primarily among men who have sex with men (MSM). However, there is a lack of awareness of the use of inhaled nitrites in this population and the possible complications and health disparities it carries. This case report highlights the use of inhaled nitrites in an MSM male with an emphasis on the complications induced by this product, including severe hemolytic anemia and methemoglobinemia. Followed by a review of both acute therapy and preventative therapy by increasing provider awareness.

\section{Case presentation:}

A 62-year-old man with a past medical history of glucose-6 phosphate dehydrogenase (G6PD) deficiency presented to the emergency department with atypical chest pain. He was tachypneic and hypotensive with laboratory evidence of end organ damage. He had an acute drop in hemoglobin with elevated bilirubin concerning for acute hemolytic anemia. His arterial blood gas was significant for elevated methemoglobin. The patient reported recent use of "poppers" (inhaled nitrite) which is associated with formation of methemoglobin and hemolytic anemia. Given the severity of his symptoms and elevated methemoglobin, he met criteria for methylene blue administration. However, his G6PD deficiency is a contraindication to methylene blue and the patient was treated conservatively with a positive outcome.

\section{Conclusion:}

The following report presents a unique scenario in which a G6PD deficient patient presented with hemolytic anemia and methemoglobinemia after recreational use of inhaled nitrites. The case was complicated with the management challenge of methemoglobinemia in a patient with G6PD deficiency. Prior literature has shown that the use of nitrites is a predictor for high-risk sexual behavior and is associated with positive human immunodeficiency virus (HIV) status. Increasing provider awareness for appropriate counseling is of importance.

\section{Background:}

Inhaled nitrites, referred to as "poppers", are substances of recreational use tracing as far back as the nineteenth century when they were used to heighten stimulation and induce muscle relaxation.[1] Anal sphincter relaxation and the facilitation of penile erection rendered inhaled nitrites a popular drug amongst MSM.[1] Nitrites can also act as potent oxidants leading to a functional anemia by inducing methemoglobinemia through oxidizing hemoglobin from ferrous to ferric form, hindering it incapable of carrying oxygen.[1] Furthermore, hemolysis can occur due to oxidative stress. [2] Although, this is a reported complication, the frequency and morbidity of symptomatic methemoglobinemia with inhaled nitrites are poorly documented.

In one case series review, twenty-five cases of methemoglobinemia associated with inhaled nitrates were assessed with three mortalities suspected to be from cardiac arrest.[1] This complication has been seen more so with patients with underlying anemias, such as G6PD deficiency, the most common genetic deficiency in the world.[2] G6PD deficiency predisposes affected patients to develop acute hemolytic anemia with the administration of oxidative agents. This is due to the function of G6PD and its importance in the initial step in the pentose-phosphate pathway of glycolysis with production of glutathione.[3] Although some preparations of inhaled nitrites (e.g. "Rush") are known to cause hemolysis in G6PD deficient patients, not all of these volatile nitrites are absolutely contraindicated in this population.[4] Much of this is due to variation of regulation of nitrite compounds globally despite evidence that inhaled nitrites have become more prominent for sexual recreational use since the turn of the century.[5]

A Germany based study found that $35 \%$ of men who identify as homosexual or bisexual reported lifetime use of recreational inhaled nitrates.[6] Prior studies have shown that the use of recreational inhaled nitrites among men who identify as homosexual or bisexual was associated with increased risk of unsafe sexual encounters and higher rates of HIV.[6, 7, 8] This case report highlights the complications seen with inhaled nitrites in the MSM community, the challenge it poses with therapy in the G6PD deficient population and to increase provider awareness of inhaled nitrite use and its possible consequences. 


\section{Case Presentation:}

A 62-year-old man, with a reported history of G6PD deficiency, coronary artery disease status post drug eluting stent on clopidogrel, congestive heart failure with reduced ejection fraction, HIV, end stage renal disease on hemodialysis, presented to the emergency department after developing 30 minutes of atypical chest pain associated with one time emesis. He admitted to using recreational "poppers" (inhaled amyl nitrite) for the first time prior to presentation but denied other substance abuse or medication changes. On arrival the patient was hypotensive, with tachypnea and hypoxemia requiring supplemental oxygen. His exam was concerning for dry mucous membranes, scleral icterus, and severe diffuse jaundice.

He was admitted to the intensive care unit where blood work showed hemoglobin of $7.2 \mathrm{~g} / \mathrm{dL}$ (decreased from his baseline of $10.5 \mathrm{~g} / \mathrm{dL}$ ). He had thrombocytopenia, which was stable from baseline. Total bilirubin was $10.5 \mathrm{mg} / \mathrm{dl}$ with direct bilirubin component of $4.6 \mathrm{mg} / \mathrm{dl}$ and alkaline phosphatase was $179 \mathrm{mU} / \mathrm{ml}$. Initial lactic acid was $3.7 \mathrm{mmol} / \mathrm{L}$. An arterial blood gas (ABG) was delayed by several hours but eventually showed a pH of 7.494, pCO2 $28.9 \mathrm{mmHg}, \mathrm{p} 0272.5 \mathrm{mmHg}$ at Fio2 of $28 \%$ and a lactic acid level that increased to $8.3 \mathrm{mmol} / \mathrm{L}$ and a methemoglobin level of $1.5 \%$, which was mildly elevated with normal being less than $1 \%$.

To further investigate his anemia a peripheral blood smear was obtained showing anisopoikilocytosis and red blood cells (RBCs) with Heinz bodies as well as a few schistocytes. He was transfused one unit of packed RBCs with appropriate response to $8.1 \mathrm{~g} / \mathrm{dL}$. Hemolysis labs were obtained showing a retic percent high at $6 \%$, his reticulocyte count was elevated at $144 \mathrm{~K} / \mathrm{mm}^{3}$, total bilirubin increased to $14 \mathrm{mg} / \mathrm{dl}$. D-dimer was normal at $3.85 \mathrm{mcg} / \mathrm{mL}$, fibrinogen mildly elevated at $316 \mathrm{mg} / \mathrm{dl}$, partial thromboplastin time was 37.7 seconds, prothrombin time was 20.2 seconds, International normalized ratio (INR) was 1.7, haptoglobin was $<8 \mathrm{mg} / \mathrm{dL}$, and moderately elevated lactate dehydrogenase $(\mathrm{LDH})$ at $524 \mathrm{U} / \mathrm{L}$. A direct coombs test was negative. Urine drug screen was negative. Computed tomography angiography of the abdomen/pelvis was unremarkable for an acute process.

His severe symptomatic hemolytic anemia was suspected from underlying G6PD deficiency and methemoglobinemia in the setting of recent nitrite use. His methemoglobinemia being $1.5 \%$, was lower than expected due to the delay in obtaining the arterial blood gas. Our patient met the criteria for treatment with methylene blue based on his severe symptoms and medical history. However, this was contraindicated in the presence of G6PD deficiency and the next line treatment with ascorbic acid would also risk further hemolysis. It was decided in consultation with hematology to continue conservative therapy. The patient's lactic acid levels peaked at $11 \mathrm{mmol} / \mathrm{L}$ which was attributed to end-organ damage from hypoperfusion secondary to severe hemolytic anemia. His hypotension and lactic acidosis resolved with volume resuscitation and hemodialysis. Subsequent arterial blood gas results showed a decrease in methemoglobin percentage and lactate acid.

The patient was successfully transferred from the intensive care unit to the general ward where he was eventually discharged home. Two months later, he followed up as an outpatient and his most recent hemoglobin was $10.6 \mathrm{~g} / \mathrm{dL}$ and his total bilirubin was $1 \mathrm{mg} / \mathrm{dl}$. Although the patient remains compliant with hemodialysis sessions, he has not followed up with hematology. His most recent clinic notes do not indicate any current symptoms.

\section{Discussion:}

Amyl nitrite induced hemolytic anemia has been documented in both patients that have underlying anemia, particularly those with G6PD deficiency, and those without.[1, 3, 9-15] A prior in vitro experiment of a case and two controls of healthy volunteers whose blood sample was exposed to amyl nitrite resulted in Heinz bodies in all red blood cells, some hemolysis and brown discoloration of the red blood cells, indicating methemoglobin formation in both the case and the controls.[9] This study also observed a dose dependent relationship between amyl nitrite and hemolysis. This is an important observation as we utilize nitrites in diagnostic modalities and margin of safety is of importance.[9] Currently, it has been shown that $30 \mathrm{~mL}$ of amyl nitrite is needed to induce hemolytic anemia.[11]

Hemolytic anemia secondary to inhaled amyl nitrite is treated with supportive care, however, methemoglobinemia is typically treated with intravenous methylene blue of 1-2 $\mathrm{mg} / \mathrm{kg}$ over a 5-minute period. The indication for methylene blue therapy is based on the absolute methemoglobin levels (>30\%), or in symptomatic patients with any level.[16] In severe cases that do not respond to methylene blue therapy, other options include exchange transfusion and hyperbaric oxygen therapy.[16] Specifically, therapy for patients with G6PD deficiency differ as they are unable to utilize methylene blue due to their low levels of NADPH.[3] Therapies for 
these patients include conservative therapy, exchange transfusion or hyperbaric oxygen. This is important to note as some hospitals are limited in resources and may not have the capabilities to provide such therapy.

Along with acute therapy, preventative therapy is of utter importance. Currently, there is a lack of awareness amongst primary care providers concerning MSM patients and their use of poppers. The use of inhaled nitrites has been associated with an increased risk of HIV in the MSM population. $[17,18,19]$ The risk of HIV transmission can increase threefold in the setting of nitrites use, as it increases the rate of unprotected sexual encounters. [20-22] Finally, it is important to note that a study revealed that up to $55.4 \%$ of patients who have used inhaled nitrites did not know that it carried potential for side effects and an increased risk of HIV transmission due to risky sexual behaviors. [23] It can be considered a public health effort to increase awareness of nitrite use in the MSM amongst providers for proper counseling and for more targeted questions to this population as literature has shown that MSM are less likely to divulge this kind of information.

\section{List Of Abbreviations:}

Men who have sex with men (MSM)

Glucose-6 phosphate dehydrogenase (G6PD)

Human immunodeficiency virus (HIV)

Nicotinamide adenine dinucleotide phosphate (NADPH)

Red blood cells (RBCs)

International normalized ratio (INR)

Lactate dehydrogenase (LDH) was $524 \mathrm{U} / \mathrm{L}$

\section{Declarations}

1. Ethics approval and consent to participate

Not applicable

2. Consent for publication

Consent was obtained from patient for publication

3. Availability of data and material

Not applicable

4. Compete interests

The authors declare that they have no competing interest

5. Funding

None

6. Author Contribution

All authors have equality contributing to writing the case report, literature search, editing and approved the final copy.

7. Acknowledgement

none 


\section{References}

1. Hunter $\mathrm{L}$, Gordge L, Dargan PI, Wood DM. Methaemoglobinaemia associated with the use of cocaine and volatile nitrites as recreational drugs: a review. Br J Clin Pharmacol. 2011;72(1):18-26.

2. Youngster I, Arcavi L, Schechmaster R, Akayzen Y, Popliski H, Shimonov J, et al. Medications and Glucose-6-Phosphate Dehydrogenase Deficiency. Drug Saf. 2010;33(9):713-26.

3. Wong A, Koutsogiannis Z, Greene S, Mcintyre S. A case of hemolysis and methemoglobinemia following amyl nitrite use in an individual with G6PD deficiency. Journal of Acute Medicine. 2013;3(1):23-5.

4. Giorgetti R. When "Chems" Meet Sex: A Rising Phenomenon Called "ChemSex ... Internet]. benthamscience. [cited 2020Jun12]. Available from: http://europepmc.org/articles/PMC5771052.

5. Romanelli F, Smith KM, Thornton AC, Pomeroy C. Poppers: Epidemiology and Clinical Management of Inhaled Nitrite Abuse. Pharmacotherapy. 2004;24(1):69-78.

6. Clutterbuck D, Gordan D. Substance use and unsafe sex amongst homosexual men in ... Internet]. Research Gate. [cited 2020Jun12]. Available from:

https://www.researchgate.net/publication/11888074_Substance_use_and_unsafe_sex_amongst_homosexual_men_in_Edinburgh.

7. Mcfarland W, Kellogg TA, Dilley J, Katz MH. Estimation of Human Immunodeficiency Virus (HIV) Seroincidence among Repeat Anonymous Testers in San Francisco. Am J Epidemiol. 1997;146(8):662-4.

8. Colfax GN, Mansergh G, Guzman R, Vittinghoff E, Marks G, Rader M, et al. Drug Use and Sexual Risk Behavior Among Gay and Bisexual Men Who Attend Circuit Parties: A Venue-Based Comparison. JAIDS Journal of Acquired Immune Deficiency Syndromes. 2001;28(4):373-9.

9. Filliatre L, Broséus J, Pissard S, Mekki C, Feugier P, Perrin J. Amyl nitrite inhalation, a "volatile" anemia. Am J Hematol. 2016;91(4):448\&\#8211.

10. Brandes J, Bufill J, Pisciotta A. Amyl nitrite-induced hemolytic anemia [Internet]. Science Direct. 2004 [cited 2020Jun12]. Available from: https://www-sciencedirect-com.proxygw.wrlc.org/science/article/pii/0002934389902842.

11. Graves TD, Mitchell S. Acute Haemolytic Anaemia after Inhalation of Amyl Nitrite. J R Soc Med. 2003;96(12):594-5.

12. Costello C, Pourgourides E, Youle M. Amyl nitrite induced acute haemolytic anaemia in HIV-antibody positive man. International Journal of STD AIDS. 2000;11(5):334-5.

13. Jørgensen KA, Lawesson SO. Amyl Nitrite and Kaposi's Sarcoma in Homosexual Men. N Engl J Med. 1982;307(14):893-4.

14. Lycka B. Amyl and Butyl Nitrites and Telangiectasia in Homosexual Men. Ann Intern Med. 1987;106(3):476.

15. Mcmanus T. Amyl Nitrite Use By Homosexuals. The Lancet. 1982;319(8270):503.

16. Wexler P. Nitrites. In: Encyclopedia of toxicology. Amsterdam: Elsevier, Academic Press; 2014.

17. Drumright LN, Gorbach PM, Little SJ, Strathdee SA. Associations Between Substance Use, Erectile Dysfunction Medication and Recent HIV Infection Among Men Who have Sex with Men. AIDS Behav. 2007;13(2):328-36.

18. Koblin BA, Chesney MA, Husnik MJ, Bozeman S, Celum CL, Buchbinder S, et al. High-Risk Behaviors Among Men Who Have Sex With Men in 6 US Cities: Baseline Data From the EXPLORE Study. Am J Public Health. 2003;93(6):926-32.

19. Purcell DW, Moss S, Remien RH, Woods WJ, Parsons JT. Illicit substance use, sexual risk, and HIV-positive gay and bisexual men: differences by serostatus of casual partners. Aids. 2005;19(Supplement 1).

20. Li D, Yang X, Zhang Z, Qi X, Ruan Y, Jia Y, et al. Nitrite Inhalants Use and HIV Infection among Men Who Have Sex with Men in China. Biomed Res Int. 2014;2014:1-9.

21. Choi KH, Operario D, Gregorich SE, Mcfarland W, Mackellar D, Valleroy L. Substance Use, Substance Choice, and Unprotected Anal Intercourse among Young Asian American and Pacific Islander Men Who Have Sex with Men. AIDS Educ Prev. 2005;17(5):41829.

22. Dirks H, Esser S, Borgmann R, Wolter M, Fischer E, Potthoff A, et al. Substance use and sexual risk behaviour among HIV-positive men who have sex with men in specialized out-patient clinics. HIV Medicine. 2012.

23. Zhang Z, Zhang L, Zhou F, Li Z, Yang J. Knowledge, attitude, and status of nitrite inhalant use among men who have sex with men in Tianjin, China. BMC Public Health. 2017;17(1). 